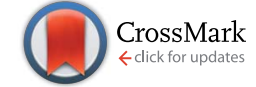

Cite this: RSC Adv., 2017, 7, 7640

\title{
VUV/UV light inducing accelerated phenol degradation with a low electric input $\uparrow$
}

\begin{abstract}
Mengkai Li, ${ }^{\text {ab }}$ Dong Wen, ${ }^{a}$ Zhimin Qiang ${ }^{\star a}$ and John Kiwi ${ }^{\star b}$
This study presents the first evidence for the accelerated degradation of phenol by Fenton's reagent in a minifluidic VUV/UV photoreaction system (MVPS). A low-pressure mercury lamp used in the MVPS led to a complete degradation of phenol within 4-6 min. The $\mathrm{HO}^{\circ}$ and $\mathrm{HO}_{2}$ ' originating from both Fenton's reagent and VUV photolysis of water were identified with suitable radical scavengers. The effects of initial concentrations of phenol, $\mathrm{H}_{2} \mathrm{O}_{2}$ and $\mathrm{Fe}^{3+}$ as well as solution $\mathrm{pH}$ on phenol degradation kinetics were examined. Increasing the initial phenol concentration slowed down the phenol degradation, whereas increasing the initial $\mathrm{H}_{2} \mathrm{O}_{2}$ or $\mathrm{Fe}^{3+}$ concentration accelerated the phenol degradation. The optimal solution $\mathrm{pH}$ was 3.7. At both 254 and $185 \mathrm{~nm}$, increasing phenol concentration enhanced its absorption for the incident photons. The reaction mechanism for the degradation of phenol was suggested consistent with the results obtained. This study indicates that the VUV/UV photo-Fenton process has potential applications in the treatment of industrial wastewater containing phenol and related aromatic pollutants.
\end{abstract}

Received 30th October 2016

DOI: $10.1039 / c 6 r a 26043 h$

www.rsc.org/advances
The degradation of phenol(s) by AOPs at current remains slow and inefficient in spite of recent improvements in reactor technology, lamp design and other engineering aspects. Fenton and photo-Fenton studies in homogeneous/heterogeneous systems leading to phenol degradation have increased in recent years. Esplugas et al. reported a time of $c a .10 \mathrm{~min}$ for phenol degradation. ${ }^{23}$ More recently, Zazo et al. reported a time of $c a .4 \mathrm{~h}$ for a complete degradation of phenol by Fenton's reagent. ${ }^{24}$ The authors also reported the phenol degradation intermediates: catechol, hydroquinone, $p$-benzoquinone and resorcinol, followed by short organic-acids branched or not before the final mineralization. ${ }^{24}$ Pontes et al. reported phenol degradation within $40 \mathrm{~min}$ in homogeneous solution, ${ }^{25}$ and by Friedrich et al. within 45 min. ${ }^{26}$ Heterogeneous Fenton and photo-Fenton using Fe-clinoptilolite led to a phenol reduction within $35 \mathrm{~min},{ }^{27}$ while clay pillared-Fe led to a phenol reduction within 120 min..$^{28}$ Pillared montmorillonite Fe and clay/silica/ zeolite reduced phenol within 60 and $120 \mathrm{~min}$, respectively. ${ }^{29,30}$

The mechanism for the homogeneous catalysis of $\mathrm{H}_{2} \mathrm{O}_{2}$ leading to highly oxidative radicals in the dark has been reviewed. ${ }^{31-33}$ The fully hydrated $\mathrm{Fe}\left(\mathrm{H}_{2} \mathrm{O}\right)_{6}{ }^{3+}$ complex was reported as a catalytic species in the Fenton system at $\mathrm{pH}<3 .{ }^{34} \mathrm{At}$ $\mathrm{pH} \leq 3.5$, the complexes $\mathrm{Fe}(\mathrm{OH})\left(\mathrm{H}_{2} \mathrm{O}\right)_{5}{ }^{2+}$ and $\mathrm{Fe}(\mathrm{OH})_{2}\left(\mathrm{H}_{2} \mathrm{O}\right)_{4}{ }^{+}$ interact with $\mathrm{H}_{2} \mathrm{O}_{2}$ in the Fenton system, which has been comprehensively described. ${ }^{35,36}$ These Fe-aqua complexes have optical absorption up to $390 \mathrm{~nm} .^{7,8}$ The basic Fenton reactions are presented in eqn (1)-(4), whilst eqn (5) and (6) refer to the photo-Fenton reactions. Note that in eqn (4) and (5), $\mathrm{Fe}(\mathrm{OH})^{2+}$ represents a simplified form of $\mathrm{Fe}(\mathrm{OH})\left(\mathrm{H}_{2} \mathrm{O}\right)_{5}{ }^{2+}$.

$$
\mathrm{Fe}^{2+}+\mathrm{H}_{2} \mathrm{O}_{2} \rightarrow \mathrm{Fe}^{3+}+\mathrm{HO}^{\cdot}+\mathrm{OH}^{-}, k_{1}=76 \mathrm{M}^{-1} \mathrm{~s}^{-1}
$$

$\dagger$ Electronic supplementary information (ESI) available. See DOI: $10.1039 / \mathrm{c} 6 \mathrm{ra} 26043 \mathrm{~h}$
${ }^{a}$ Key Laboratory of Drinking Water Science and Technology, Research Center for rcees.ac.cn; Tel: +861062849632

${ }^{b}$ Ecole Polytechnique Fédérale de Lausanne, EPFL-SB-ISIC-GPAO, Station 6, CH-1015 Lausanne, Switzerland. E-mail: john.kiwi@pfl.ch; john.kiwi@epfl.ch; Tel: +41 21 


$$
\begin{gathered}
\mathrm{Fe}^{3+}+\mathrm{H}_{2} \mathrm{O}_{2} \rightarrow \mathrm{FeOOH}^{2+}+\mathrm{H}^{+}, k_{2}=2 \times 10^{-2} \mathrm{M}^{-1} \mathrm{~s}^{-1} \\
\mathrm{FeOOH}^{2+} \rightarrow \mathrm{Fe}^{2+}+\mathrm{HO}_{2} \\
\mathrm{Fe}^{3+}+\mathrm{H}_{2} \mathrm{O} \rightarrow \mathrm{Fe}(\mathrm{OH})^{2+}+\mathrm{H}^{+} \\
\mathrm{Fe}(\mathrm{OH})^{2+}+h \nu \rightarrow \mathrm{Fe}^{2+}+\mathrm{HO}^{\cdot} \\
\mathrm{H}_{2} \mathrm{O}_{2}+h \nu \rightarrow 2 \mathrm{HO}^{\circ}
\end{gathered}
$$

The photo-Fenton reactions presented in eqn (5) and (6) generate additional $\mathrm{HO}^{*}$ through the light activated reduction of $\mathrm{Fe}(\mathrm{OH})^{2+}$ and the direct photolysis of $\mathrm{H}_{2} \mathrm{O}_{2}$. This accelerates the degradation of organic compounds compared to the dark Fenton system..$^{34}$ The $\mathrm{HO}^{\circ}$ generated led in the first reaction step to an aromatic ring addition to the phenol, leading to the hydroxyl-cyclohexadienyl radical. ${ }^{37,38}$

The objective of this study was to achieve an accelerated degradation of phenol by the Fenton's reagent $\left(\mathrm{Fe}^{2+/ 3+} / \mathrm{H}_{2} \mathrm{O}_{2}\right)$ in a more advanced photo-reactor by way of VUV/UV irradiation. Due to a short degradation time and a low electric input, this VUV/UV photo-Fenton process only required a low energy consumption. The experiments were carried out in a minifluidic VUV/UV photoreaction system (MVPS), which provided VUV/UV or UV irradiation with an accurate quantification of UV fluence. The light absorption by each of the solution components in the photo-reactor was determined as well as the identity of intermediate oxidative radicals. The effects of initial phenol concentration, initial $\mathrm{H}_{2} \mathrm{O}_{2}$ concentration, and solution $\mathrm{pH}$ on phenol degradation kinetics were examined in detail. The reaction mechanism leading to phenol degradation was also suggested.

\section{Experimental section}

\section{Chemical reagents and analytical methods}

All solutions were prepared in ultrapure water produced from a Milli-Q system (Advantage A10, Millipore, USA). Chemicals used were of at least reagent grade and purchased from SigmaAldrich (St. Louis, MO, USA) or Thermo Fisher Scientific (Fair Lawn, NJ, USA). Fenton experiments were conducted employing $\mathrm{FeCl}_{3}$ and $\mathrm{H}_{2} \mathrm{O}_{2}(\sim 35 \%$ by weight). The initial $\mathrm{pH}$ was adjusted by $\mathrm{NaOH}$ and $\mathrm{HCl}$ solutions. 1,4-Benzoquinone (BQ) and tertbutanol (TBA) were used as $\mathrm{O}_{2}{ }^{--}$and $\mathrm{HO}^{-}$scavengers, respectively. Uridine $(0.12 \mathrm{mM})$ and methanol $(0.10 \mathrm{mM})$ were utilized as chemical actinometers to determine the UV fluence rate output from the MVPS.

Phenol concentration was determined by using a highperformance liquid chromatograph coupled with a photodiode-array detector (HPLC/DAD, Agilent Technologies, US). Methanol concentration was determined by a gas chromatograph equipped with a flame ionization detector (GC/FID, Shimadzu, Japan). Uridine concentration was measured by light absorption at $664 \mathrm{~nm}$ on a UV-Vis spectrophotometer (2600, Shimadzu, Japan) directly linked to the MVPS. $\mathrm{H}_{2} \mathrm{O}_{2}$ concentration was measured by Titanium(Iv) oxysulfate $\left(\mathrm{TiOSO}_{4}\right)$ with a detection limit of $0.01 \mathrm{mg} \mathrm{L^{-1 } . 3 9}$ Total organic carbon (TOC) was analyzed with a TOC analyzer (TOC-VCPH, Shimadzu, Japan).

\section{VUV/UV and UV irradiations in the MVPS}

To overcome the limitations of traditional batch VUV/UV photoreactors, an innovative design of a bench-scale MVPS was developed in our previous study (see Fig. S1†). ${ }^{39,40}$ The photoreactor chamber was cylindrical (length $=300 \mathrm{~mm}$, outer diameter $=40 \mathrm{~mm}$ ) with a jacketed quartz-wall. An $8 \mathrm{~W}$ lowpressure mercury lamp (arc length $=200 \mathrm{~mm}$, Wanhua Co., Zhejiang, China) manufactured by synthetic quartz was housed in the center of the photo-reactor, which could emit both 185 (VUV) and $254 \mathrm{~nm}$ (UV) beams. Cooling water was recirculated through the outer chamber at a constant temperature to maintain stable VUV and UV outputs from the LP lamp. A synthetic quartz tube (i.e., VUV/UV tube, high VUV transmittance) and a Ti-doped silica tube (i.e., UV tube, no VUV transmittance) were installed parallel to the lamp in the photoreactor chamber with the same distance $(c a .5 \mathrm{~mm})$ to the lamp surface. The inner diameter and length of both tubes were 2 and $100 \mathrm{~mm}$, respectively. The reaction solution flowing through the VUV/UV and UV tubes could receive the 185/254 $\mathrm{nm}$ and the $254 \mathrm{~nm}$ irradiations, respectively. Nearly same UV (at $254 \mathrm{~nm}$ ) fluence rate (FR) could be obtained in the VUV/UV and UV tubes because both tubes had a very high $254 \mathrm{~nm}$ transmittance and were positioned at the same distance to the lamp surface. Nitrogen gas was flushed through the inner chamber of the photo-reactor, to eliminate the air absorption (primarily $\mathrm{O}_{2}$ ) of VUV and thus maximize the VUV light reaching the reaction solution. By using the chemical actinometers of uridine and methanol, the VUV and UV FRs (i.e., $E_{\mathrm{o}, \mathrm{VUV}}$ and $\left.E_{\mathrm{o}, \mathrm{UV}}\right)$ were determined to be 1.7 and $14.5 \mathrm{~mW} \mathrm{~cm}^{-2}$, respectively. An UV-Vis spectrophotometer (2600, Shimadzu, Japan) was installed in the MVPS to provide online absorbance measurements.

\section{Experimental procedures and reduction equivalent exposure time}

After a 15 min lamp equilibration period, the phenol solution of $50 \mathrm{~mL}$ was circulated in the MVPS by a peristaltic pump. Samples of $1 \mathrm{~mL}$ each were taken out at preselected times for chemical analysis. During the MVPS runs, the reaction solution was recirculated sequentially through the exposure section (i.e., the VUV/UV or UV tube) and the dark section until a desired fluence was reached. The reduction equivalent exposure time $\left(t_{\text {ree }}, \mathrm{s}\right)$ is defined as the total reaction time $(t, \mathrm{~s})$ multiplied by the ratio of the exposure volume of the operation tube $\left(\pi r^{2} h\right.$, $\left.\mathrm{m}^{3}\right)$ to the total sample volume $\left(V, \mathrm{~m}^{3}\right)$ :

$$
t_{\text {ree }}=\frac{\pi r^{2} h}{V} t
$$

where $r$ and $h$ are the radius and the length of the VUV/UV (or UV) tube, respectively. In other words, $t_{\text {ree }}$ represents the exposure time when the whole reaction solution receives the exposure under the same exposure conditions (i.e., the same $E_{\mathrm{o}, \mathrm{UV}}$

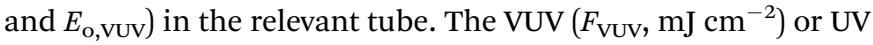

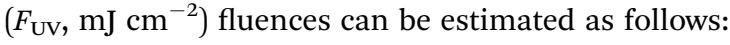




$$
\begin{gathered}
F_{\mathrm{VUV}}=E_{\mathrm{o}, \mathrm{VUV}} t_{\text {ree }} \\
F_{\mathrm{UV}}=E_{\mathrm{o}, \mathrm{UV}} t_{\text {ree }}
\end{gathered}
$$

\section{Results and discussion}

Phenol absorption spectrum and degradation kinetics and TOC reduction in the MVPS

Fig. 1 shows the absorption spectra of $\mathrm{H}_{2} \mathrm{O}_{2}, \mathrm{FeCl}_{3}$ and phenol. Note that the mercury resonance lines at $185 / 254 \mathrm{~nm}$ (i.e., in the VUV/UV tube) or $254 \mathrm{~nm}$ (i.e., in the UV tube) irradiations were used throughout this study. The molar absorption coefficients of $\mathrm{H}_{2} \mathrm{O}_{2}$, phenol and $\mathrm{Fe}(\mathrm{III})$ increased towards shorter wavelengths. The light absorption of $\mathrm{H}_{2} \mathrm{O}_{2}$ was so low that it could not absorb a significant amount of VUV/UV and UV photons at the low concentrations (i.e., mostly $0.147 \mathrm{mM}$ ) used in the MVPS. The Fe $(\mathrm{d}-\mathrm{d})$ transitions take place in the nanosecond time scale, and the intensity of these transitions giving rise to the $\mathrm{Fe}(\mathrm{III})$-spectrum depends on the counter-ion, $\mathrm{pH}$ and $\mathrm{Fe}$ (III) concentration. ${ }^{\mathbf{4 1 , 4 2}}$

Fig. 2a shows the phenol degradation by the dark Fenton, UV or VUV/UV photolysis, UV photo-Fenton, and VUV/UV photoFenton processes at an initial $\mathrm{pH}$ of 3.7. The VUV/UV in the absence of the Fenton's reagent $\left(\mathrm{Fe}^{2+/ 3+} / \mathrm{H}_{2} \mathrm{O}_{2}\right)$ induced phenol degradation due to the VUV $(185 \mathrm{~nm})$ light generating $\mathrm{HO}^{\circ}$ from the photolysis of water. ${ }^{\mathbf{4 3 , 4 4}}$ Without UV and VUV irradiation, little phenol degradation was found although both $\mathrm{Fe}^{3+}$ and $\mathrm{H}_{2} \mathrm{O}_{2}$ were present. UV and VUV/UV photo-Fenton processes led to a complete phenol degradation within 6-8 min. The photochemical behavior of the $\mathrm{Fe}(\mathrm{III})$-aqua complexes plays a determining role in pollutant degradation. ${ }^{35,36} \mathrm{At}$ $\mathrm{pH} 3.7$ in this study, $\mathrm{Fe}\left(\mathrm{H}_{2} \mathrm{O}\right)_{6}{ }^{3+}$ was partially transformed into $\mathrm{Fe}(\mathrm{III})(\mathrm{OH})\left(\mathrm{H}_{2} \mathrm{O}\right)_{5}{ }^{2+}$, which was able to undergo ligand-to-metal-charge-transfer. This transformation depends on the excitation wavelength and involves inner sphere photo-induced electron transfer leading

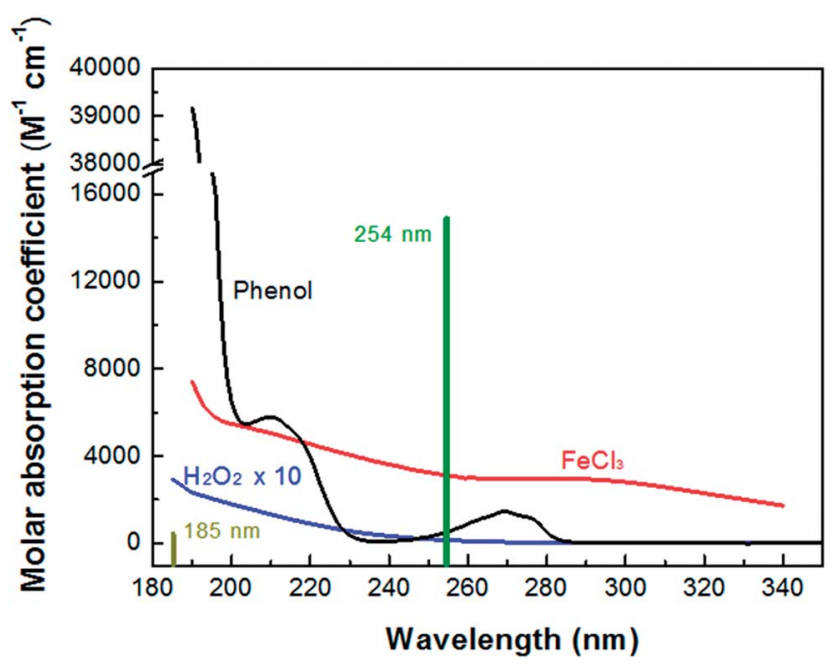

Fig. 1 Absorption spectra of $\mathrm{H}_{2} \mathrm{O}_{2}, \mathrm{FeCl}_{3}$ and phenol and mercury resonance lines at 254 and $185 \mathrm{~nm}$ of the low-pressure mercury lamp.
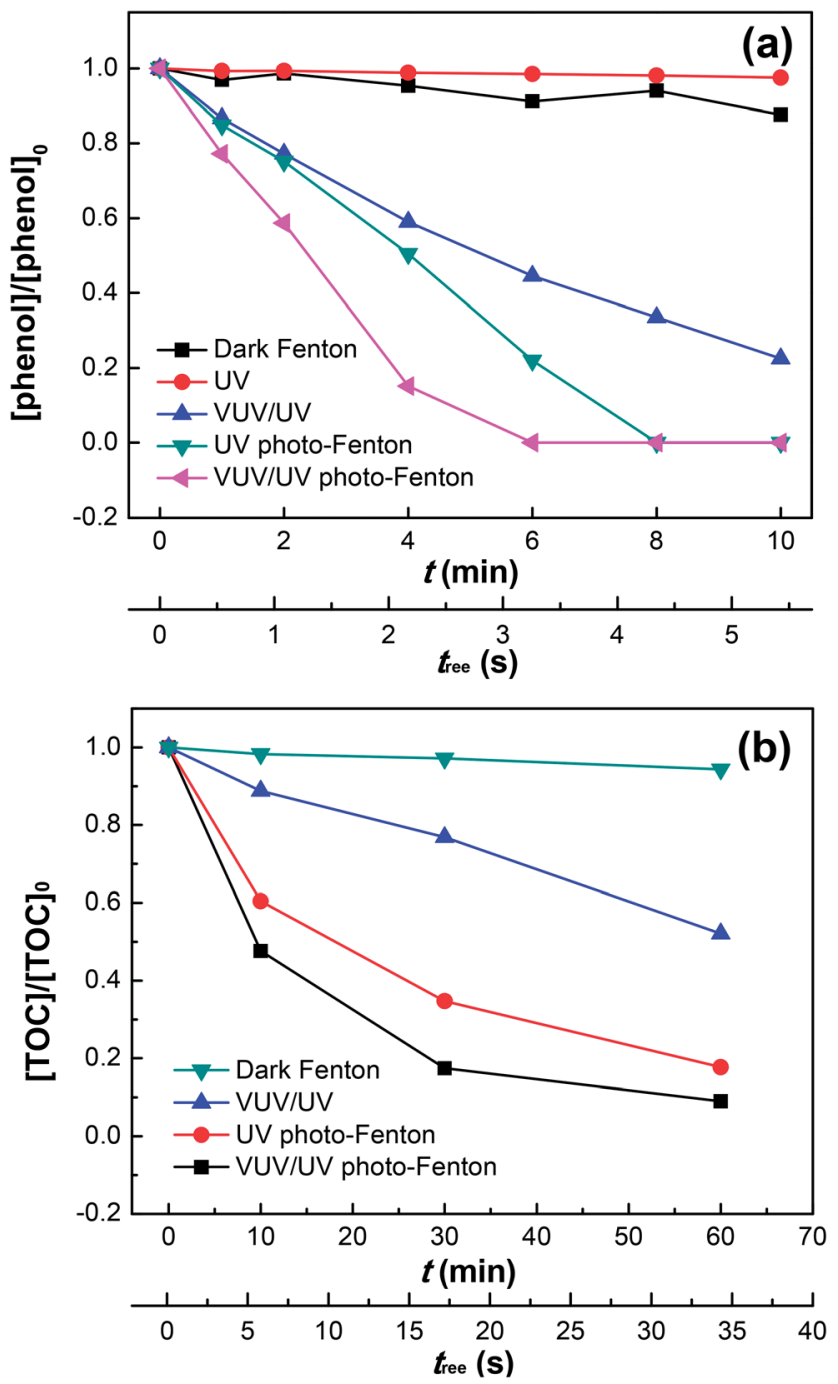

Fig. 2 Phenol degradation (a) and TOC removal (b) in the dark Fenton, UV, VUV/UV, UV photo-Fenton and VUV/UV photo-Fenton processes at $\mathrm{pH}_{0}=3$ 3.7. Experimental conditions: (a) [phenol] $]_{0}=0.011 \mathrm{mM}$, $\left[\mathrm{H}_{2} \mathrm{O}_{2}\right]_{0}=0.147 \mathrm{mM},\left[\mathrm{Fe}^{3+}\right]_{0}=0.05 \mathrm{mM}$; and (b) [phenol $]_{0}=$ $0.055 \mathrm{mM},\left[\mathrm{H}_{2} \mathrm{O}_{2}\right]_{0}=0.735 \mathrm{mM},\left[\mathrm{Fe}^{3+}\right]_{0}=0.25 \mathrm{mM}$.

to the $\mathrm{Fe}(\mathrm{II})$-aqua complex (i.e., $\mathrm{Fe}(\mathrm{II})\left(\mathrm{H}_{2} \mathrm{O}\right)_{6}{ }^{2+}$ ) and $\mathrm{HO}^{\circ}$, as shown in eqn (5) above.

The HO• leading to phenol degradation was generated by the VUV $\left(185 \mathrm{~nm}\right.$ ) photolysis of water and the $\mathrm{Fe}^{3+}$ photo-reduction. In addition, VUV also generates $\mathrm{H}^{*}$ and $\mathrm{e}_{\mathrm{aq}}{ }^{-}$in aqueous solutions due to homolysis and water ionization. ${ }^{43,44}$ Fig. 2a shows that UV (254 $\mathrm{nm})$ by itself did not lead to phenol degradation. The VUV (185 $\mathrm{nm}$ ) photons preferentially react with water (concentration of $55.6 \mathrm{M})$ compared to phenol $(0.011 \mathrm{mM})$. Hence, the VUV (185 nm) photon absorption by phenol only contributed marginally to the phenol degradation (see Table 1). When $\mathrm{H}_{2} \mathrm{O}_{2}$ and $\mathrm{Fe}^{3+}$ were added during phenol degradation under UV or VUV/UV irradiation, the higher efficiency of phenol degradation could be explained by the effective $\mathrm{Fe}(\mathrm{II}) / \mathrm{Fe}(\mathrm{III})$ inter-conversion and subsequently the higher generation of oxidative radicals. The $\mathrm{Fe}(\mathrm{OH})\left(\mathrm{H}_{2} \mathrm{O}\right)_{5}{ }^{2+}$ may also react with dissolved oxygen in the reaction solution to form $\mathrm{O}_{2}{ }^{--}$, thus 
Table 1 Solution parameters determining the light absorption during phenol degradation in the MVPS ${ }^{a}$

\begin{tabular}{lllllll}
\hline Reactant & $C(\mathrm{mM})$ & $\varepsilon_{254}\left(\mathrm{M}^{-1} \mathrm{~cm}^{-1}\right)$ & $\varepsilon_{185}\left(\mathrm{M}^{-1} \mathrm{~cm}^{-1}\right)$ & $A_{254}$ & $A_{185}$ & $P_{254}(\%)$ \\
\hline $\mathrm{H}_{2} \mathrm{O}$ & 55600 & 0.0002 & 0.03 & 0.01 & 1.8 & 5.7 \\
Phenol & 0.011 & 472 & 39178 & 0.005 & 0.431 & 3.0 \\
$\mathrm{H}_{2} \mathrm{O}_{2}$ & 0.147 & 19 & 341 & 0.003 & 0.050 & 1.6 \\
$\mathrm{FeCl}_{3}$ & 0.05 & 3140 & 7250 & 0.157 & 0.363 & 89.7 \\
Total & & & & 0.175 & 2.644 & 100 \\
\end{tabular}

${ }^{a} C$ is the molar concentration of each solution component; $\varepsilon_{254}$ and $\varepsilon_{185}$ are the molar absorption coefficient of each solution component at 254 and $185 \mathrm{~nm}$, respectively; $A_{254}$ and $A_{185}$ are the absorbance of each solution component for $1 \mathrm{~cm}$ optical path length at 254 and $185 \mathrm{~nm}$, respectively $\left(A_{254}\right.$ $=\varepsilon_{254} \times C$ and $\left.A_{185}=\varepsilon_{185} \times C\right) ; P_{254}$ is the ratio of $A_{254}$ of a specific solution component to the sum of $A_{254}$ of all solution components $\left(i . e\right.$. , total $A_{254}$ $=0.175)$; and $P_{185}$ is the ratio of $A_{185}$ of a specific solution component to the sum of $A_{185}$ for all solution components $\left(i . e\right.$., total $\left.A_{185}=2.644\right)$.

enhancing the phenol degradation. It has been reported that dissolved oxygen is able to enhance Fenton/photo-Fenton reactions..$^{37,38}$

Fig. $2 \mathrm{~b}$ presents the mineralization of phenol under different irradiation conditions up to $60 \mathrm{~min}$. Only $90 \%$ of the initial phenol was converted into $\mathrm{CO}_{2}$ in the VUV/UV photo-Fenton process. This suggests the existence of long-lived organic intermediates in the reaction solution, such as catechol, hydroquinone, $p$-benzoquinone and resorcinol as reported by Zazo et al. ${ }^{24}$ which probably accounts for the tail after $30 \mathrm{~min}$. Note that a higher concentration of phenol, $\mathrm{H}_{2} \mathrm{O}_{2}$ and $\mathrm{Fe}^{3+}$ was used here than that in Fig. 2a, because TOC could only be measured accurately at a higher phenol concentration (i.e., $0.055 \mathrm{mM}$ ). The total mineralization reaction of phenol can be written as follows:

$$
\mathrm{C}_{6} \mathrm{H}_{5} \mathrm{OH}+14 \mathrm{H}_{2} \mathrm{O}_{2} \rightarrow 6 \mathrm{CO}_{2}+17 \mathrm{H}_{2} \mathrm{O}
$$

The fractions of the incident photons absorbed by each solution component (i.e., $\mathrm{Fe}^{3+}, \mathrm{H}_{2} \mathrm{O}_{2}$, phenol, and $\mathrm{H}_{2} \mathrm{O}$ ) during the TOC removal (Fig. 2b) is shown Fig. S2 (ESI $\dagger$ ).

\section{Effects of initial phenol, $\mathrm{H}_{2} \mathrm{O}_{2}$ and $\mathrm{Fe}^{3+}$ concentrations on phenol degradation kinetics}

Fig. 3a shows phenol degradation as a function of the initial phenol concentration in the range of $0.011-0.266 \mathrm{mM}$. High concentrations of phenol decreased the degradation rate, due to the competition for the oxidative radicals in solution. In addition, the increasing phenol concentration would induce a higher fraction of UV (254 $\mathrm{nm}$ ) photons absorbed by phenol, leaving less photons for the photo-reduction of $\mathrm{Fe}^{3+}$ (see eqn (5)). Similarly, this would also lower the amount of $\mathrm{HO}^{*}$ generated by the VUV photolysis of water. Therefore, at high concentrations of phenol, the radicals generated by the Fenton's reagent $\left(\mathrm{Fe}^{2+/ 3+} / \mathrm{H}_{2} \mathrm{O}_{2}\right)$ would not be enough to degrade effectively an increased amount of phenol. Although secondary reactions due to these oxidative radicals still led to the degradation of phenol, only a low efficiency was observed., ${ }^{5,74}$

Fig. $3 \mathrm{~b}$ shows that the degradation rate of phenol increased with increasing $\mathrm{H}_{2} \mathrm{O}_{2}$ concentration, which implies that the interaction of $\mathrm{H}_{2} \mathrm{O}_{2}$ with phenol was significant. This can be explained by the photolysis of the intermediate complex/ exciplex $\left[\mathrm{Fe}^{3+} \cdots\right.$ phenol $\left.\cdots \mathrm{H}_{2} \mathrm{O}_{2}\right]$ in solution. ${ }^{23-27} \mathrm{H}_{2} \mathrm{O}_{2}$ could also scavenge $\mathrm{HO}^{*}$ in solution, ${ }^{\mathbf{1 1 - 1 4}}$ but this was not significant at $\mathrm{H}_{2} \mathrm{O}_{2}$ concentrations used in this study (i.e., $\leq 2.941 \mathrm{mM}$ ). Hence, no inhibition of phenol degradation was seen in Fig. $3 \mathrm{~b}$.

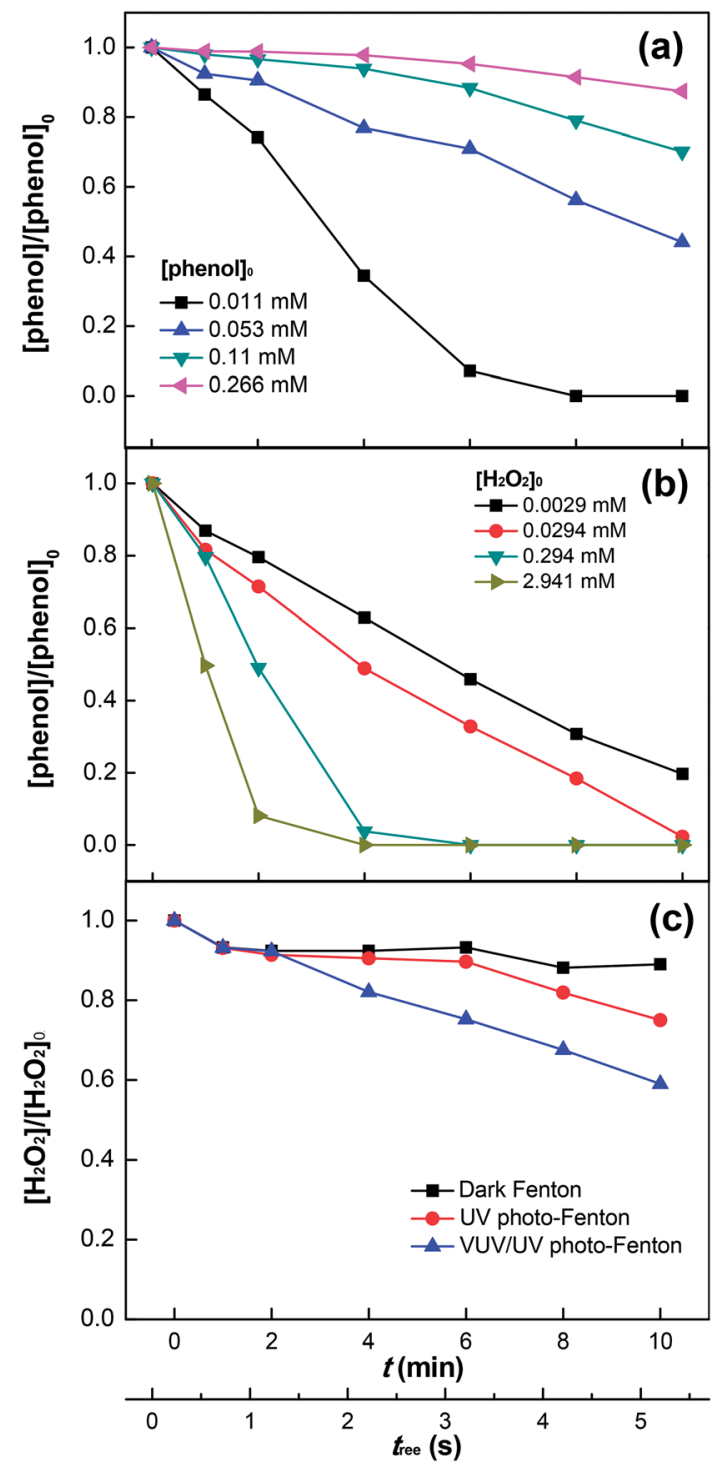

Fig. 3 Effects of initial concentrations of phenol (a) and $\mathrm{H}_{2} \mathrm{O}_{2}$ (b) on phenol degradation as well as $\mathrm{H}_{2} \mathrm{O}_{2}$ decomposition (c) in the VUV/UV photo-Fenton process. Experimental conditions: [phenol] $]_{0}=$ $0.011 \mathrm{mM},\left[\mathrm{H}_{2} \mathrm{O}_{2}\right]_{0}=0.147 \mathrm{mM},\left[\mathrm{Fe}^{3+}\right]_{0}=0.05 \mathrm{mM}$, and $\mathrm{pH}_{0}=3.7$. 
Moreover, the increasing $\mathrm{Fe}^{3+}$ concentration (up to $0.5 \mathrm{mM}$ ) could also enhance the phenol degradation (see Fig. S3, ESI $\dagger$ ), which allowed $\mathrm{Fe}^{3+}$ to absorb more 254 and $185 \mathrm{~nm}$ photons (see eqn (5)), thus enhancing the $\mathrm{HO}^{*}$ generation. Concomitantly, this would also decrease the fraction of photons absorbed by $\mathrm{H}_{2} \mathrm{O}_{2}$ and subsequently the $\mathrm{HO}^{*}$ generation through $\mathrm{H}_{2} \mathrm{O}_{2}$ photolysis (see eqn (6)). Comparatively, the negative effect of the decreased $\mathrm{H}_{2} \mathrm{O}_{2}$ photolysis was less significant. The $\mathrm{Cl}^{-}$ ions added with $\mathrm{FeCl}_{3}$ could substitute water in the first coordination sphere of $\mathrm{Fe}(\mathrm{OH})\left(\mathrm{H}_{2} \mathrm{O}\right)_{5}{ }^{2+}$ to yield mixed ligand complexes, such as $\mathrm{FeCl}\left(\mathrm{H}_{2} \mathrm{O}\right)_{5}{ }^{2+}$ and $\mathrm{FeCl}_{2}\left(\mathrm{H}_{2} \mathrm{O}\right)_{4}{ }^{+} \cdot{ }^{41,45,46}$

Fig. 3c shows the $\mathrm{H}_{2} \mathrm{O}_{2}$ consumption during phenol degradation. It is readily seen that using the Fenton's reagent in the dark led to a small $\mathrm{H}_{2} \mathrm{O}_{2}$ consumption due to the slow radical generation (i.e., $\mathrm{HO}^{\circ}$ and $\mathrm{HO}_{2}{ }^{\circ}$ ) (see eqn (1) and (3)). A higher $\mathrm{H}_{2} \mathrm{O}_{2}$ consumption was observed when UV irradiation was applied. The reason is that more $\mathrm{H}_{2} \mathrm{O}_{2}$ was consumed by $\mathrm{Fe}^{2+}$, which was effectively photo-generated from $\mathrm{Fe}^{3+}$ (see eqn (4) and (5)), and by $\mathrm{HO}^{*}$ in the radical scavenging process as well. Under VUV/UV irradiation, a significant increase in $\mathrm{H}_{2} \mathrm{O}_{2}$ consumption was observed compared to that under UV irradiation, because of the enhanced $\mathrm{Fe}^{3+}$ reduction, water photolysis, ${ }^{\mathbf{4 3 , 4 4}}$ and $\mathrm{H}_{2} \mathrm{O}_{2}$ photolysis by the VUV light.

The VUV light generates radicals and ions in water as reported by previous researchers. ${ }^{43,44}$ VUV photolysis of water leads to both radicals $\mathrm{HO}^{\circ}, \mathrm{HO}_{2}{ }^{\circ}, \mathrm{O}_{2}{ }^{--}, \mathrm{H}^{*}$ and stable species such as $\mathrm{H}_{2} \mathrm{O}_{2}$ and $\mathrm{O}_{2}$. In this study, the kinetics of phenol degradation depended on the absorbers in the UV and VUV regions (see Table 1). Even though the $\mathrm{H}_{2} \mathrm{O}_{2} / \mathrm{UV}$ process presents similarities with the VUV/UV process, there are substantial differences: (a) in the $\mathrm{H}_{2} \mathrm{O}_{2} / \mathrm{UV}$ process, the photolysis of $\mathrm{H}_{2} \mathrm{O}_{2}$ only generates $\mathrm{HO}^{\circ}$; whereas in the VUV/UV process, the photolysis of water generates ${ }^{\circ} \mathrm{OH}, \mathrm{H}^{\cdot}$ and $\mathrm{e}_{\mathrm{aq}}{ }^{-}\left(\mathrm{H}_{2} \mathrm{O}+h \nu(185\right.$ $\mathrm{nm}) \rightarrow{ }^{\circ} \mathrm{OH}+\mathrm{H}^{+}+\mathrm{e}_{\mathrm{aq}}{ }^{-}$), which modifies the observed radical reactions. ${ }^{43,44}$ The direct addition of $\mathrm{e}_{\mathrm{aq}}{ }^{-}$to $\mathrm{H}_{2} \mathrm{O}_{2}$ during VUV irradiation (i.e., $\mathrm{H}_{2} \mathrm{O}_{2} \rightarrow \mathrm{HO}_{2}{ }^{-}+\mathrm{H}^{+}$) was not possible in the Marcus inverse region, ${ }^{8}$ because the activation energy necessary for this reaction was not available.

The decomposition of $\mathrm{H}_{2} \mathrm{O}_{2}$ produced the oxidative radicals $\mathrm{HO}^{\circ}$ (in the first place) and $\mathrm{HO}_{2}{ }^{\circ}$ (to a lesser degree), as demonstrated by the scavenging experiments with TBA and BQ (see Fig. 4). The decomposition of $\mathrm{H}_{2} \mathrm{O}_{2}$ involves eqn (1), (2) and (6) as well as additionally the reactions reported in literature: ${ }^{31,37,47}$

$$
\begin{gathered}
\mathrm{H}_{2} \mathrm{O}_{2}+\mathrm{HO}^{\cdot} \rightarrow \mathrm{H}_{2} \mathrm{O}+\mathrm{HO}_{2}^{\cdot} \\
\mathrm{H}_{2} \mathrm{O}_{2}+\mathrm{HO}_{2}^{\cdot} \rightarrow \mathrm{H}_{2} \mathrm{O}+\mathrm{O}_{2}+\mathrm{HO}^{\cdot} \\
\mathrm{Fe}^{2+}+\mathrm{HO}_{2}^{\cdot} \rightarrow \mathrm{Fe}^{3+}+\mathrm{HO}_{2}^{-} \\
\mathrm{Fe}^{3+}+\mathrm{HO}_{2}^{\cdot} \rightarrow \mathrm{Fe}^{2+}+\mathrm{H}^{+}+\mathrm{O}_{2} \\
2 \mathrm{HO}^{\cdot} \rightarrow \mathrm{H}_{2} \mathrm{O}_{2}
\end{gathered}
$$

Eqn (11) and (15) denote the scavenging and recombination of $\mathrm{HO}^{\circ}$, respectively. As the $\mathrm{H}_{2} \mathrm{O}_{2}$ concentration increased, both reactions fostered the decomposition of $\mathrm{H}_{2} \mathrm{O}_{2}$.

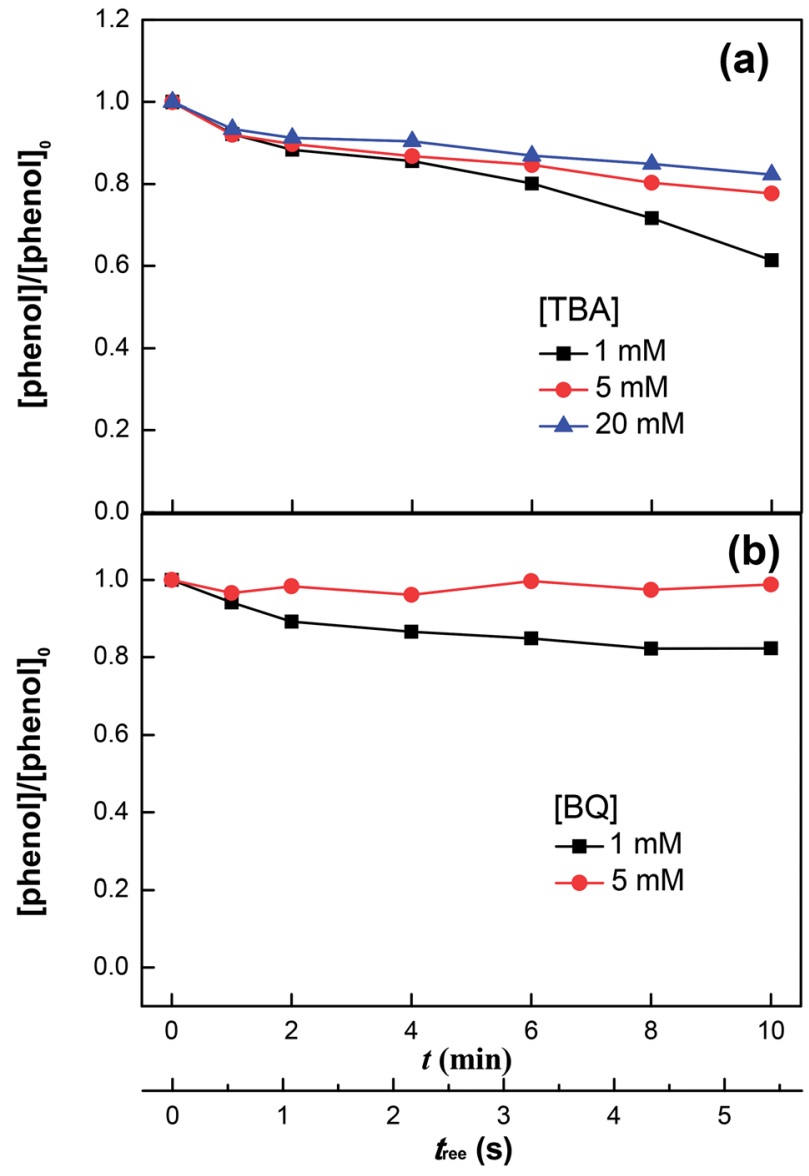

Fig. 4 Phenol degradation in the VUV/UV photo-Fenton process in the presence of tert-butanol (TBA) (a) and benzoquinone (BQ) (b). Experimental conditions: [phenol $]_{0}=0.011 \mathrm{mM},\left[\mathrm{H}_{2} \mathrm{O}_{2}\right]_{0}=0.147 \mathrm{mM}$, $\left[\mathrm{Fe}^{3+}\right]_{0}=0.05 \mathrm{mM}$, and $\mathrm{pH}_{0}=3.7$.

\section{Identification of oxidative radicals produced in the VUV/UV photo-Fenton process}

Fig. 4a shows the phenol degradation under VUV/UV irradiation with TBA used as a $\mathrm{HO}^{\circ}$ scavenger. $\mathrm{HO}^{-}$is scavenged by TBA with a reaction rate of $1.9 \times 10^{9} \mathrm{M}^{-1} \mathrm{~s}^{-1}$ and reacts with phenol at a diffusion controlled reaction rate of $9.6 \times 10^{9} \mathrm{M}^{-1} \mathrm{~S}^{-1} \cdot{ }^{47} \mathrm{It}$ is readily seen that increasing the TBA concentration inhibited phenol degradation due to the quenching of the $\mathrm{HO}^{\circ}$.

Fig. $4 \mathrm{~b}$ shows the phenol degradation in the presence of $\mathrm{BQ}$, an $\mathrm{HO}_{2}{ }^{\circ}$ scavenger. The phenol degradation slowed down at higher BQ concentrations. BQ scavenges $\mathrm{HO}_{2}{ }^{\cdot}$ with a reaction rate of $9.6 \times 10^{8} \mathrm{M}^{-1} \mathrm{~s}^{-1}$ according to the reaction:

$$
\mathrm{BQ}+\mathrm{HO}_{2}^{\cdot} \rightarrow \mathrm{BQ}^{\cdot-}+\mathrm{H}^{+}+\mathrm{O}_{2}
$$

\section{Mechanism for phenol degradation by Fenton's reagent under VUV/UV irradiation}

Fig. 5a shows the effect of initial $\mathrm{pH}$ on phenol degradation in the VUV/UV photo-Fenton process. Both $\mathrm{Fe}(\mathrm{OH})^{2+}$ reduction and $\mathrm{H}_{2} \mathrm{O}_{2}$ hydrolysis under UVC light (see eqn (5) and (6)), 
generated additional $\mathrm{HO}^{\circ}$ compared to the dark Fenton system. ${ }^{31,34,46}$ The Fe(III)-aqua complexes present different molar absorption coefficients and optical absorption wavelength ranges as a function of the solution $\mathrm{pH} .^{35,36}$ This in turn induced a different rate of phenol degradation and quantum yield as a function of $\mathrm{pH}$. The highest phenol degradation rate was found at $\mathrm{pH}$ 3.7. At this $\mathrm{pH}$, the initial fully coordinated $\mathrm{Fe}^{3+}$ ion under strongly acidic conditions, $\mathrm{Fe}\left(\mathrm{H}_{2} \mathrm{O}\right)_{6}{ }^{3+}$, could incorporate an $\mathrm{OH}^{-}$group in its structure leading to the formation of $\mathrm{Fe}(\mathrm{OH})\left(\mathrm{H}_{2} \mathrm{O}\right)_{5}{ }^{2+} \cdot{ }^{35,36,42}$ Under UVC light irradiation, $\mathrm{Fe}(\mathrm{OH})\left(\mathrm{H}_{2}-\right.$ $\mathrm{O}_{5}{ }^{2+}$ led to the formation of $\mathrm{HO}^{\cdot}$ (see eqn (5)). The relatively
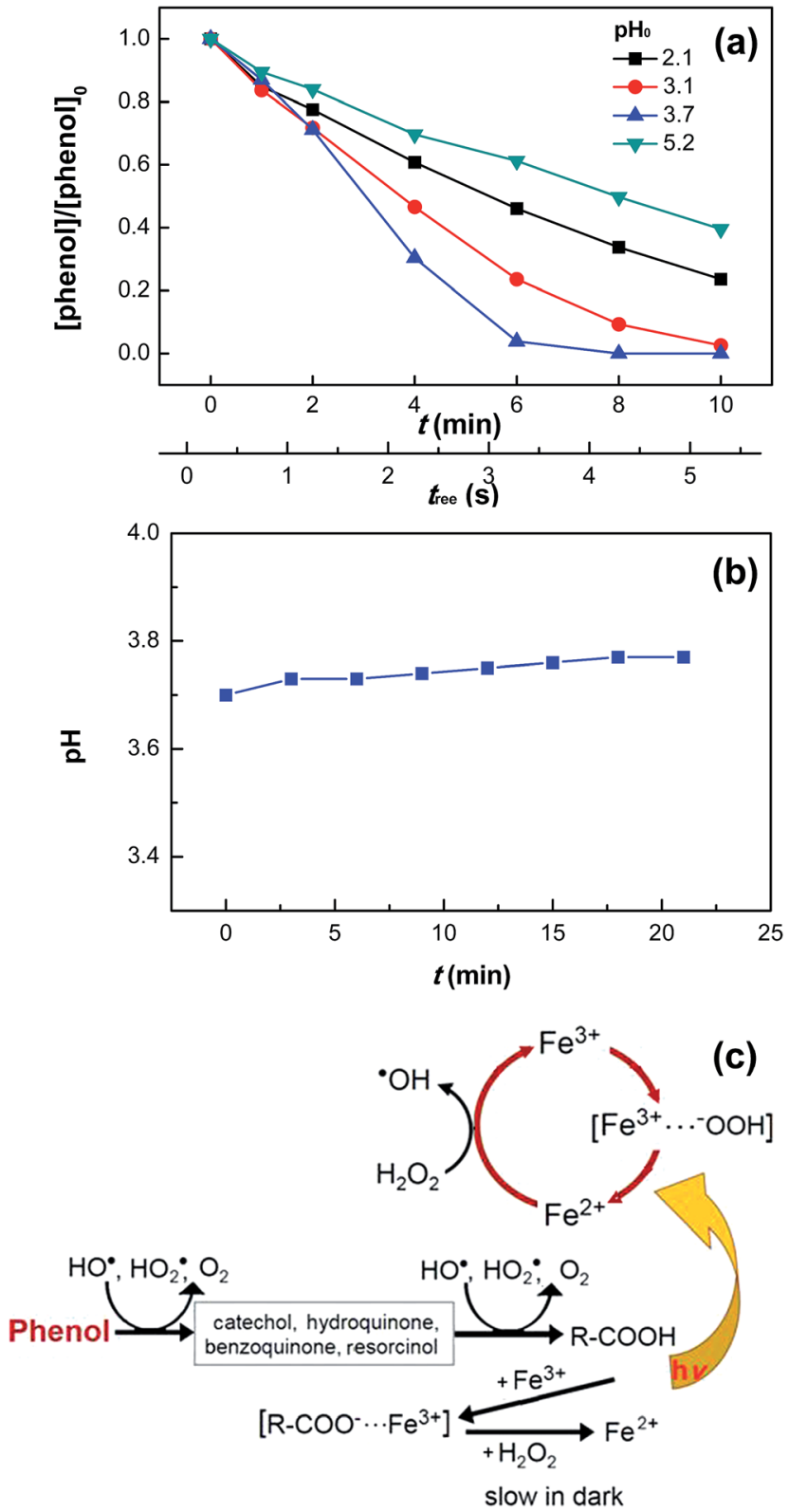

Fig. 5 Phenol degradation at various initial $\mathrm{pH}$ values (a) and $\mathrm{pH}$ variation $\left(\mathrm{pH}_{0}=3.7\right)(b)$ in the VUV/UV photo-Fenton process as well as proposed reaction mechanisms for the dark Fenton and VUV/UV photo-Fenton processes (c). Experimental conditions: [phenol] $]_{0}=$ $0.011 \mathrm{mM},\left[\mathrm{H}_{2} \mathrm{O}_{2}\right]_{0}=0.147 \mathrm{mM}$, and $\left[\mathrm{Fe}^{3+}\right]_{0}=0.05 \mathrm{mM}$. slower phenol degradation rates at pHs 2.1 and 3.1 were probably due to the acidic Fe-aqua complexes substituted by $\mathrm{Cl}^{-}$in the first coordination sphere such as $\mathrm{FeCl}\left(\mathrm{H}_{2} \mathrm{O}\right)_{5}{ }^{2+}$ and $\mathrm{FeCl}_{2}(-$ $\left.\mathrm{H}_{2} \mathrm{O}\right)_{4}{ }^{2+} \cdot{ }^{47}$ At $\mathrm{pH}$ 5.2, the Fe-aqua complex, $\mathrm{Fe}(\mathrm{OH})_{2}\left(\mathrm{H}_{2} \mathrm{O}\right)_{4}{ }^{+}$, incorporated progressively one more $\mathrm{OH}^{-}$group slowing down the phenol degradation rate. ${ }^{48}$ The degradation of other organic pollutants by photo-Fenton processes have been reported recently. ${ }^{49,50}$

Fig. 5b shows that during phenol degradation under VUV/UV irradiation, the solution $\mathrm{pH}$ moved slightly to more basic values. This suggests that the phenol degradation was mainly due to the $\mathrm{HO}^{*} / \mathrm{OH}^{-}$conversion. Fenton reactions induced the hydroxylation of the aromatic ring of phenol through the hydroxy-cyclohexadienyl radical by the addition of $\mathrm{HO}^{\circ}$, which subsequently led to the formation of quinones and other intermediates shown in Fig. $5 \mathrm{c}$ and also found during phenol degradation by the Fenton's reagent by Zazo et al. ${ }^{24} \mathrm{~A}$ mechanistic cycle for phenol degradation in the dark and by a photoFenton system under UVC irradiation is suggested in Fig. 5c.

Light absorption by each solution component during phenol degradation with various initial concentrations

Although the effect of initial phenol concentration on its degradation kinetics was already examined in Fig. 3a, the specific contribution of the highly oxidative radical species leading to phenol degradation has not been completely elucidated. This remains a controversial issue. Fig. 6a shows the fraction variation of the $185 \mathrm{~nm}$ photons absorbed by each solution component as a function of the phenol concentration. For the degradation of low-concentration phenol (i.e., [phenol $]_{0}$ $=0.011 \mathrm{mM}$ ) by the VUV/UV photo-Fenton process, the fraction of $185 \mathrm{~nm}$ photons absorbed by water was $68.1 \%$, while those by phenol and $\mathrm{FeCl}_{3}$ were $16.3 \%$ and $13.7 \%$, respectively, indicating that the effect of the additional VUV irradiation was the HO generation from VUV photolysis of water as compared to that of the UV photo-Fenton process. The enhancement for $\mathrm{Fe}^{3+}$ reduction and direct photolysis of phenol by the VUV (185 $\mathrm{nm})$ light was rather small. When the phenol concentration increased to $0.266 \mathrm{mM}$, phenol could absorb $82.5 \%$ of the $185 \mathrm{~nm}$ photons. In this case, the $\mathrm{HO}^{\circ}$ generation through VUV photolysis of water became much less important.

Fig. $6 \mathrm{~b}$ shows the fraction of the $254 \mathrm{~nm}$ photons absorbed by each component in the solution as a function of phenol concentration. Because of the low molar absorption coefficient of water at $254 \mathrm{~nm}$ (see Table 1), the photon absorption by water was not significant. For a low phenol concentration, $\mathrm{Fe}^{3+}$ could absorb most of the $254 \mathrm{~nm}$ photons. However, when the phenol concentration increased from 0.011 to $0.266 \mathrm{mM}$, the fraction of the $254 \mathrm{~nm}$ photons absorbed by phenol increased from $3.0 \%$ to $42.5 \%$, which considerably decreased the generation of $\mathrm{HO}^{\circ}$ through eqn (4)-(6).

The results of photon absorption by the components in solution show that under UV and VUV irradiations, the 254 and $185 \mathrm{~nm}$ photons absorbed by phenol itself played an important role in phenol degradation, especially when the phenol concentration was high. The ionization of phenol requires 


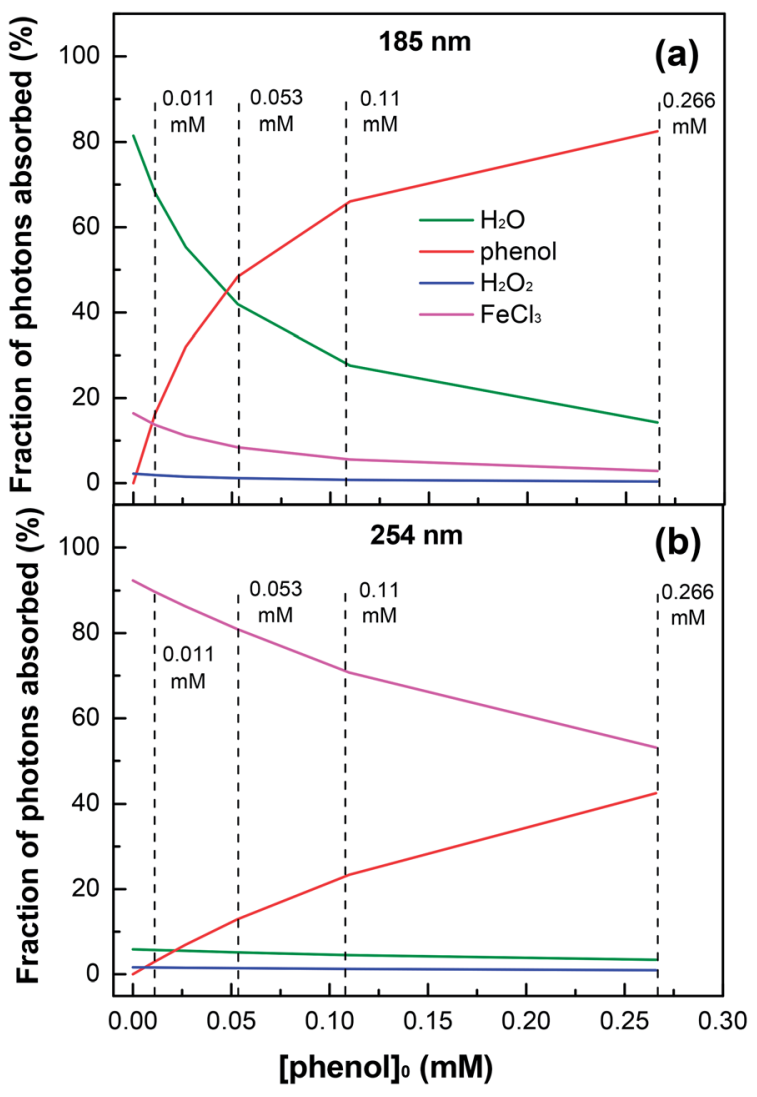

Fig. 6 Fractions of 185 (a) and $254 \mathrm{~nm}$ (b) photons absorbed by each solution component as a function of initial phenol concentration in the VUV/UV photo-Fenton process. Experimental conditions: $\left[\mathrm{H}_{2} \mathrm{O}_{2}\right]_{0}=$ $0.735 \mathrm{mM},\left[\mathrm{Fe}^{3+}\right]_{0}=0.25 \mathrm{mM}$, and $\mathrm{pH}_{0}=3.7$.

$8.50 \mathrm{eV}$ and may go through either a mono-photonic or biphotonic absorption process. The $185 \mathrm{~nm}$ light is made up of $6.70 \mathrm{eV}$ photons; therefore, it might induce a mono-photonic ionization of phenol. For the $254 \mathrm{~nm}$ photons $(4.87 \mathrm{eV})$, a biphotonic ionization of phenol was likely to occur. The ionization reactions are presented in eqn (17)-(19). These results demonstrate that the phenol concentration strongly affected its degradation kinetics and the VUV/UV photo-Fenton process was most suitable for the treatment of dilute phenol solutions.

$$
\begin{gathered}
\text { Phenol }+h \nu \rightarrow \text { phenol }^{+}+\mathrm{e}^{\mathrm{aq}^{-}} \\
\text {Phenol }+\mathrm{e}_{\mathrm{aq}}{ }^{-} \rightarrow \text { phenol }^{-} \\
\mathrm{e}_{\mathrm{aq}}{ }^{-}+\mathrm{O}_{2}+\mathrm{H}^{+} \rightarrow \mathrm{HO}_{2}{ }^{\cdot}
\end{gathered}
$$

\section{Conclusions}

This study addressed the optimization of the solution parameters leading to the enhanced abatement of phenol in a minifluidic VUV/UV photoreaction system. The phenol degradation required a reduced consumption of electricity because the VUV light was made full use. By the VUV/UV mercury resonant lines
(185/254 nm), water and $\mathrm{H}_{2} \mathrm{O}_{2}$ generated the highly oxidative radicals $\left(\mathrm{HO}^{\circ}\right.$ and $\mathrm{HO}_{2}{ }^{\circ}$ ) leading to phenol degradation. The generation of these oxidative radicals was further increased in the presence of $\mathrm{Fe}^{3+}$ ions in the photo-Fenton processes. The oxidative radicals which intervened in the phenol degradation were identified. In addition, the fraction of the incident photons absorbed by each solution component was quantified. For a dilute phenol solution $(0.011 \mathrm{mM})$, the fraction absorbed by phenol was $16.3 \%$ for the VUV photons $(185 \mathrm{~nm})$ and $3.0 \%$ for the UV photons $(254 \mathrm{~nm})$, while for a high-concentration phenol solution $(0.266 \mathrm{mM})$, the fraction increased to $82.5 \%(185 \mathrm{~nm}$ photons) and to $42.5 \%$ ( $254 \mathrm{~nm}$ photons). Due to a relatively low electrical energy used to generate the oxidative radicals to abate phenol, the VUV/UV photo-Fenton process has potential applications in the treatment of industrial wastewater containing phenol and related aromatic pollutants.

\section{Acknowledgements}

This work was supported by the National Natural Science Foundation of China (21590814, 51408592, 51611540344), National Geographic Air and Water Conservation Fund (GEFC23-15), and the People Program (Marie Curie Actions) of the European Union's Seventh Program FP7/2007-2013 under a REA grant (Agreement No. 318926).

\section{References}

1 S. Malato, P. Fernández-Ibáñez, M. I. Maldonado, J. Blanco and W. Gernjak, Catal. Today, 2009, 147, 1-59.

2 M. R. Hoffmann, S. T. Martin, W. Y. Choi and D. W. Bahnemann, Chem. Rev., 1995, 95, 69-96.

3 H. Roques, Chemical Water Treatment: Principles and Practice, VCH Publishers Inc., New York, NY, 1996.

4 N. P. Cheremissinoff, Handbook of Water and Waste Water Treatment Technologies, Butterworth-Heinemann, Woburn, MA, 2002.

5 J. P. Scott and D. F. Ollis, Environ. Prog., 1995, 14, 88-103.

6 O. Legrini, E. Oliveros and A. M. Braun, Chem. Rev., 1993, 93, 671-698.

7 Aquatic and Surface Photochemistry, ed. G. R. Helz, R. G. Sepp and D. G. Crosby, Lewis Publishers, Boca Raton, FL, 1994.

8 W. Stumm and J. J. Morgan, Aquatic Chemistry: Chemical Equilibria and Rates in Natural Waters, John Wiley \& Sons, Inc., New York, NY, 3rd edn, 1996.

9 A. Machulek Jr, S. C. Oliveira, M. E. Osugi, V. S. Ferreira, F. H. Quina, R. F. Dantas, S. L. Oliveira, G. A. Casagrande, F. J. Anaissi, V. O. Silva, R. P. Cavalcante, F. Gozzi, D. D. Ramos, A. P. P. da Rosa, A. P. F. Santos, D. C. de Castro and J. A. Nogueira, Application of Different Advanced Oxidation Processes for the Degradation of Organic Pollutants, InTech, Sao Paulo, Brazil, 2013.

10 M. Stefan, Advanced Oxidation Processes for Water Treatment: Fundamental and Applications, IWA Publishing, Alliance House, London UK, 2017, in press.

11 A. Fujishima, X. T. Zhang and D. A. Tryk, Surf. Sci. Rep., 2008, 63, 515-582. 
12 M. Pelaez, N. T. Nolan, S. C. Pillai, M. K. Seery, P. Falaras, A. G. Kontos, P. S. M. Dunlop, J. W. J. Hamilton, J. A. Byrne, K. O'Shea, M. H. Entezari and D. D. Dionysiou, Appl. Catal., B, 2012, 125, 331-349.

13 S. Banerjee, D. D. Dionysiou and S. C. Pillai, Appl. Catal., B, 2015, 176, 396-428.

14 J. Schneider, M. Matsuoka, M. Takeuchi, J. L. Zhang, Y. Horiuchi, M. Anpo and D. W. Bahnemann, Chem. Rev., 2014, 114, 9919-9986.

15 R. W. Matthews, J. Catal., 1988, 111, 264-272.

16 Environmental Health and Toxicology; https:// sis.nlm.nih.gov, National Library of Medicine, USA, 2005.

17 G. Balasubramanian, D. D. Dionysiou, M. T. Suidan, Y. Subramanian, I. Baudin and J. M. Laine, J. Mater. Sci., 2003, 38, 823-831.

18 M. R. Wiesner, G. V. Lowry, P. Alvarez, D. Dionysiou and P. Biswas, Environ. Sci. Technol., 2006, 40, 4336-4345.

19 J. M. Rosas, F. Vicente, A. Santos and A. Romero, Chem. Eng. J., 2013, 220, 125-132.

20 G. Veréb, L. Manczinger, A. Oszkó, A. Sienkiewicz, L. Forró, K. Mogyorósi, A. Dombi and K. Hernádi, Appl. Catal., B, 2013, 129, 194-201.

21 P. Raja, M. Bensimon, A. Kulik, R. Foschia, D. Laub, P. Albers, R. Renganathan and J. Kiwi, J. Mol. Catal. A: Chem., 2005, 237, 215-223.

22 M. J. Sampaio, C. G. Silva, A. M. T. Silva, V. J. P. Vilar, R. A. R. Boaventura and J. L. Faria, Chem. Eng. J., 2013, 224, 32-38.

23 S. Esplugas, J. Giménez, S. Contreras, E. Pascual and M. Rodríguez, Water Res., 2002, 36, 1034-1042.

24 J. A. Zazo, J. A. Casas, A. F. Mohedano, M. A. Gilarranz and J. J. Rodríguez, Environ. Sci. Technol., 2005, 39, 9295-9302.

25 R. F. F. Pontes, J. E. F. Moraes, A. Machulek Jr and J. M. Pinto, J. Hazard. Mater., 2010, 176, 402-413.

26 L. C. Friedrich, C. L. P. S. Zanta, A. Machulek Jr, V. D. Silva and F. H. Quina, Sci. Agric., 2012, 69, 347-351.

27 M. Bayat, M. Sohrabi and S. J. Royaee, J. Ind. Eng. Chem., 2012, 18, 957-962.

28 C. Catrinescu, D. Arsene, P. Apopei and C. Teodosiu, Appl. Clay Sci., 2012, 58, 96-101.

29 O. B. Ayodele, J. K. Lim and B. H. Hameed, Appl. Catal., A, 2012, 413-414, 301-309.
30 S. Navalon, M. Alvaro and H. Garcia, Appl. Catal., B, 2010, 99, 1-26.

31 A. Y. Sychiov and V. G. Isac, Usp. Khim., 1995, 64, 1183-1209.

32 P. Cieśla, P. Kocot, P. Mytych and Z. Stasicka, J. Mol. Catal. A: Chem., 2004, 224, 17-33.

33 J. Sima and J. Makanova, Coord. Chem. Rev., 1997, 160, 161189.

34 G. Ruppert, R. Bauer and G. Heisler, J. Photochem. Photobiol., A, 1993, 73, 75-78.

35 A. Safarzadeh-Amiri, J. R. Bolton and S. R. Cater, Sol. Energy, 1996, 56, 439-443.

36 D. Wang, T. Oppenländer, M. G. El-Din and J. R. Bolton, Photochem. Photobiol., 2010, 86, 176-181.

37 C. Walling, Acc. Chem. Res., 1975, 8, 125-131.

38 S. Ito, A. Mitarai, K. Hikino, M. Hirama and K. Sasaki, J. Org. Chem., 1992, 57, 6937-6941.

39 M. K. Li, Z. M. Qiang, P. Hou, J. R. Bolton, J. H. Qu, P. Li and C. Wang, Environ. Sci. Technol., 2016, 50, 5849-5856.

40 M. K. Li, Z. M. Qiang, C. Pulgarin and J. Kiwi, Appl. Catal., B, 2016, 187, 83-89.

41 W. P. Kwan and B. M. Voelker, Environ. Sci. Technol., 2003, 37, 1150-1158.

42 V. Balzani and V. Carassiti, Photochemistry of Coordination Compounds, Academic Press, London, 1970.

43 S. Robl, M. Worner, D. Maier and A. M. Braun, Photochem. Photobiol. Sci., 2012, 11, 1041-1050.

44 M. Bagheri and M. Mohseni, J. Hazard. Mater., 2015, 294, 18.

45 Inorganic Chemistry: Towards the 21st Century, ACS Symposium Series, ed. M. H. Chisholm, American Chemical Society, Washington, DC, 1983, vol. 211.

46 V. Nadtochenko and J. Kiwi, Environ. Sci. Technol., 1998, 32, 3273-3281.

47 P. Wardman, J. Phys. Chem. Ref. Data, 1989, 18, 1637-1755.

48 L. M. Dorfman and G. E. Adams, National Standard Reference Data System, National Bureau of Standards 46, Washington, DC, 1973.

49 X. L. Yang, W. Chen, J. F. Huang, Y. Zhou, Y. H. Zhu and C. Z. Li, Sci. Rep., 2015, 5, 10632.

50 W. Shi, D. Du, B. Shen, C. F. Cui, L. J. Lu, L. Z. Wang and J. L. Zhang, ACS Appl. Mater. Interfaces, 2016, 8, 20831-20838. 